\title{
The Role of Internal Audit Quality in Promoting Public Sector Performance: Evidence from South Nations, Nationalities and Peoples Regional State, Ethiopia
}

\author{
Binyam Tesfaye Merkineh \\ Dean of BSTL College, Hawassa, Ethiopia \\ Tibebu Yacob Ulsido \\ Lecturer, Accounting \& Finance Department, BSTL College, Hawassa, Ethiopia \\ Kanbiro Orkaido Deyganto \\ Lecturer and Researcher, College of Business and Economics, Dilla University, Dilla, Ethiopia
}

\begin{abstract}
The quality of internal audit plays a significant role in enhancing public sector bureaus performance by bringing effective and efficient use of the public resource. So, the objective of this study was to examine the role of internal audit quality on performance of public sector bureaus in southern Ethiopia. To this end, the researcher employed quantitative research approach with explanatory research design where the effect caused by the independent variable on the dependent variable is observed through regression analysis. The primary and secondary data were collected. Then, both descriptive and inferential statistics analysis (multiple linear regression) have been done through SPSS version 21.0 in order to get the reliable research findings. Consequently, the result of regression analysis showed that out of five variables incorporated in the multiple linear regression model, four variables such as independency of internal audit, competency of internal audit staff, management support, and formal mandate of internal audit have positive and statistically significant impact on public sector performance. Whereas internal audit standard was not statistically significant. Based on the findings of the study, the researcher forwarded possible recommendations for bureaus to work on independency of internal audit, competency of internal audit staff, management support, and formal mandate of internal audit due to the fact that they are statistically significant and has positive influence public sector performance of bureaus in southern Ethiopia.
\end{abstract}

Keywords: Quality of Internal Audit, Public Sector Performance, Southern Ethiopia

DOI: $10.7176 /$ RJFA/10-17-05

Publication date:September $30^{\text {th }} 2019$

\section{Introduction}

\subsection{General Background of the Study}

Internal audit is an independent review of what other done by independent professional hired by organization itself. It is an important part of the corporate governance structure within an organization. The effective internal audit can also safeguard the firm from potential losses which affect the performance of the firm. Furthermore, internal audit plays a vital role in enhancing both good governance of public sector or private organization [1]. In other way, checking compliance with organizational police and procedures and verifying the existence of assets is the function of internal audit which boots the organizations performance [2].

In agreement with the above importance of internal audit, the work quality of internal audit unit is the key for achieving the organizational performance of public entities. Internal audit quality means use of some techniques to recognize misstatements in clients accounting system and report the misstatements which has a significant impact on the organizations' performance. To enhance the internal audit quality, the internal auditors should possess the knowledge, skills and disciplines essential for professional care in performing of internal audit activity [3]. Internal auditors should possess the right and ability to access all information in every part of the organization and their function should lies at every activities of the corporate governance system. Because, internal auditors can make line managers aware of their responsibility; it can act as a consultant in monitoring risk, identifies weakness in internal control system, and facilitates the implementation of risk management as well as internal audit contributes to the appropriateness of procedures and operations of the audited body[4].

The quality of internal audit impact has also got emphasis in Ethiopia public organizations. The Accounting and Auditing Board of Ethiopia has clearly put that quality of internal audit is base for achieving public organizations goal in particular and growth and transformation plan II or GTP two II of the country. To this end, a number of researches have been studied the internal audit issues outside Ethiopia and concluded that competency, independency, internal audit standard, competency of leadership, objectivity of internal audit staff, management support, legal mandate of internal audit and unrestricted access to audit evidence are key 
determinates of internal audit quality which has positive impact on organizational performance and internal audit effectiveness [2], [3], [6], [7], [17], [19] and [24].

This research different from others by developing multiple linear regressions in order to study the effect of internal audit key elements and their impact on public sector performance especially in selected bureaus of southern Ethiopia. Besides, there is time gap due to factors internal audit effectiveness and its effect on public sector organizational performance changed from time to time due to dramatic changes in politics, economy, technology and socio-cultural aspects of the public organizations changes from time to time. Hence, research the time gap from 2017 up to 2019 since all studies reviewed were conducted up to 2016.

When it comes to Ethiopia, a fewer researchers have conducted their study on similar topic and suggested that competency, independency, internal audit standard, objectivity of internal audit staff, management support, legal mandate of internal audit to audit evidence have positive impact on organizational performance and internal audit effectiveness [1]; [11]; [15] and [24]. The present study is unique by incorporating two more number of variable such as unrestricted access and competent leadership more than the previous Ethiopian researcher who tried to touch the topic. In addition, the current study will fill the time gap that previously conducted studies do not disclose the current time impact of internal audit quality on organizational performance due to economic, social, political, technological and organizational changes from time to time. This is way the of internal audit quality become crucial issue that requires research generally in Ethiopia and particularly in south region since there is no published research on the internal audit quality issue in the region as per the internet browse by the researchers.

As a result, conducting this research will add value for the government of Ethiopia by identifying the impact of internal audit quality on organizational performance of public bureaus of Ethiopia specifically sector bureaus in SNNPRS. To the extent that, the objective of this study is to assess the impact of internal audit quality on organizational performance of public sector bureaus in SNNPRS by filling the above mentioned gaps that enables the bureaus to improve internal audit quality. So, conducting this research would add value for the government by identifying the impact of internal audit quality on organizational performance of public bureaus of Ethiopia specifically 43 sector bureaus in Southern Ethiopia.

\subsection{Objectives of the Study}

The main purpose of this study was to examine the role of internal audit quality promoting public sector performance of southern Ethiopia. In line with the above main Objective, the specific Objective of the research are:

a). To examine the role of Independence of Internal Audit on organizational performance.

b). To analyze the role of Internal Audit competency on organizational performance.

c). To determine the role of professional Internal Audit Standard on public sector performance.

d). To investigate the effect of management support on organizational performance

e). To test the effect a Formal Mandate of Internal Audit on organizational performance.

\subsection{Justification of the Study}

The internal audit unit in any organization has a significant contribution to control any noncompliance activity in line with the established policies, plans, procedures, laws and regulations, set by organization itself, the government and any professional institutions. Internal audit quality is the use some techniques to recognize misstatements in clients (auditees) accounting system and report the misstatements which has a significant impact on the organization's operations and performance. Therefore, this research is very essential for the public sector offices in Ethiopia to be aware of all the factors that influence their performance with reference to internal audit quality. Besides, the major beneficiaries from this study are regulatory bodies and researchers in Ethiopia and the society in the globe at large.

\subsection{Empirical Review and Hypothesis}

As the main aim of this research is the effect of internal audit quality on the organizational performance in the public sectors, different authors and researcher's idea and recommendations regarding the related topic of internal audit are reviewed. The researchers has developed the research hypothesis for eight variables incorporated in the model based on empirical review as follow:

\section{(i) Independency of Internal Audit (IIA)}

Independence of internal allows the audit activity to conduct work and be perceived to conduct work without interference by the entity under audit and independence is a key factor for the internal audit activity to add value. According to research done by [17] there is positive and significant relationship between internal audit independence and performance. The other research also evidenced that there is positive relationship between independency of internal audit and good governance in public sector [22]. Hence, the researchers hypothesize that: 
H1: Independence of the internal auditor has positive and significant effect on organizational performance.

\section{(ii) Competency of Internal Audit Team (CIAS)}

The audit activity needs a professional staff that collectively has the necessary qualifications and competencies to conduct the full range of audits required by the mandate. Auditors must comply with minimum education requirements established by their relevant professional organizations and standards. The competency of internal audit staff has positive and significant relationship with performance [17], [23] and [26]. Accordingly, the researcher developed the tentative statement of the current research as:

H2: Competency of internal audit staff has positive and significant effect on organizational performance.

\section{(iii) Internal Audit standards (IAS)}

Professional audit standards, such as the international professional practices framework (IPPF) promulgated by the IIA, support the implementation of the previous elements and provide a framework to promote quality audit work that is systematic, objective, and based on evidence. Audit activities should conduct their work in accordance with recognized standards. Conformance with the standards is seen as a key factor for the internal audit activity to add value to the governance process. According to the result of study by Conformance with the standards is seen as a key factor for the internal audit activity to add value to the governance process. The internal audit activity conforms to some or all of the standards, verification of compliance with other standards or codes and Verification of Compliance with other Standards or Codes respectively [16]. So, the researchers hypothesize that:

H3: Internal audit standard has positive and significant effect on organizational performance.

\section{(iv) Management support:}

The legitimacy of the audit activity and its mission should be understood and supported by a broad range of elected and appointed public sector officials, as well as by the media and involved citizens. This means the internal audit activity is credible within the organization. In the same way, management support of internal audit department has significant impact on internal audit quality in one hand and organizational performance in other hand [8] and [23]. So that, the researchers formulated the hypothesis as:

H4: Management support has positive effect on public bureaus performance

\section{(v) Formal Mandate of Internal Audit (FM)}

Internal auditing is required by law or regulation where the organization is based was responded. The external regulatory environment may impact the capability of the internal audit activity. Specifically, having a legal mandate may give more legitimacy to the internal audit activity. The regression result of [23] showed there is positive relationship among organizational performance and formal mandate. Accordingly, it can be hypothesized as:

H5: Formal Mandate of Internal Audit has positive influence on organizational performance

\section{Conceptual framework of the study}

This section provides a conceptual frame work for this study based on literature review. It explains the key variables and relationships variables. It assumes that

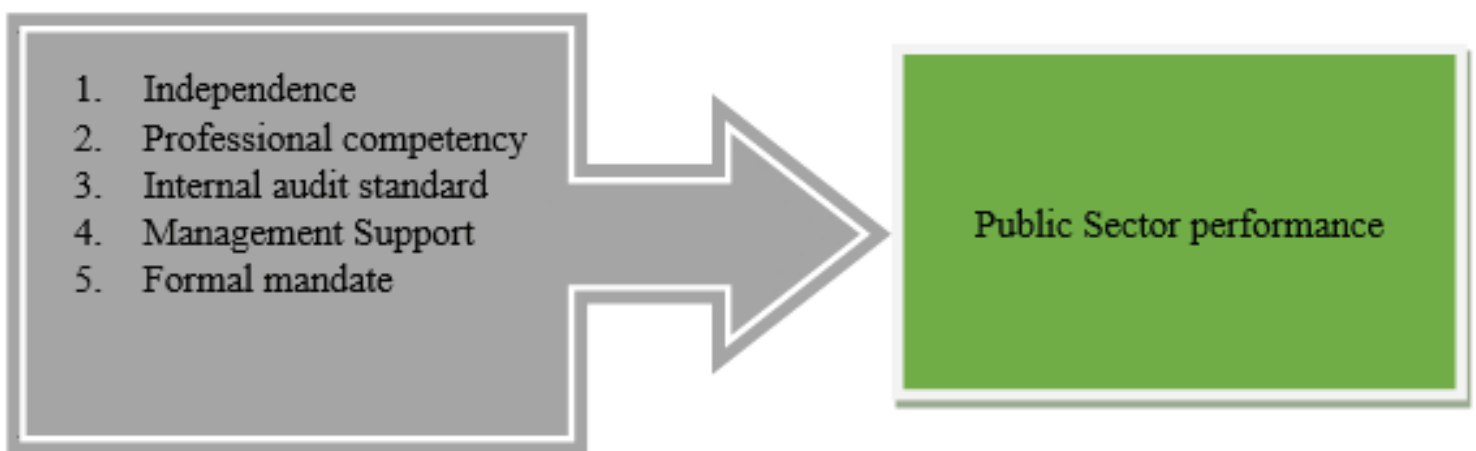

Figure 1. Conceptual Framework of the Study

Source: Own construction (2019)

\section{Methods}

\subsection{Research Approach and Design}

There are three research approaches. These are quantitative, qualitative research and mixed approaches. Quantitative research approach involving numerical or statistical data and emphasis is on the quantifiable observations of the research which is mainly objective. Whereas, qualitative research approach is an approach to gather non-numerical data in which Words and observations are used to express the reality where 'getting close to the data' and an 'in-depth' approach are key concerns. The mixed approach is the combination of both quantitative and qualitative approaches. In the current study, the researcher has employed quantitative research 
approach for the reason. A research design is the arrangement of conditions for collection and analysis of data in a manner that aims to combine relevance to the research purpose with economy in procedure. When the purpose of research is to test a research hypothesis, it is termed as hypothesis-testing research. It can be the experimental design or the non-experimental design [5]. In the research; the researcher has employed explanatory research design because, the objective of the study is to test and explain eight hypotheses about the effect of eight independent variables (independency of internal audit, competency of internal audit, internal audit standard, , management support, legal mandate of internal audit, on dependent variable (public sector performance).

\subsection{Data source and Methods of Data Collections}

In this research, the researcher used both primary and secondary data. The source of primary data was collected from respondents selected from the bureaus. While the secondary data source were published like journals, books, and thesis and unpublished like office annual reports, minuets and other materials related to the study. To collect primary data structured questionnaire an direct personal interview were used. And secondary data were collected through review of different published and unpublished materials that are related to topic.

\subsection{Target Population, Sample Size and Selection Techniques}

All selected senior coordinator and managers of projects, government finance administrator, internal audit support work process, accountants, internal auditors, finance support work process owner, internal audit support work process owner, currently working in the position of finance and audit in the selected regional sector bureaus in SNNPR. These 43 bureaus were considered as the target population of the study. To determine the sample size out of 43 sector Bureaus in southern Ethiopia, the researcher purposively selected 15 due to fact that major resources (budget of government) is allocated to them in order to achieve the Growth and Transformation plan II (GTP-II) from period 2015/2016 to 2019/2020. There are 135 internal auditors=15*9) 9 auditors in each bureaus. Then, researcher used simple random sampling technique and employed the scientific formula of (Yamane, 1967) that takes 95\% of confidence interval for sample size selected of the pupulation. This implies the sample data $95 \%$ populationdata and the remaining $5 \%$ is error this is calculated is follows:

$$
\begin{gathered}
\boldsymbol{n}=\frac{\boldsymbol{N}}{\mathbf{1}+(\boldsymbol{e}) 2 * \mathrm{~N}} \\
\text { Where: } \mathrm{n}=\text { sample size } \\
\mathrm{N}=\text { population size } \\
\mathrm{e}=\text { Precision level or sampling error }=0.05 \\
n=\frac{135}{1+(0.05)^{2} * 135}=101 \\
\text { Source: }(\text { Yamane, } 1967)
\end{gathered}
$$

Hence, the representative sample size for this study is 101 internal auditor in sector bureaus of SNNPRS.

\subsection{Operational Definition of Variables \\ Dependent Variable}

Public sector performance (PSP): In the current study, management by objectives (goal attainment) which is pure subjective measurement of organizational performance is used as an indicator of performance. Due to not availability of necessary financial data, the researchers used five point Likert scale [(from strongly agree (1), agree (2), neither agree nor disagree (3), disagree (4), strongly disagree (5)], to state agreement or disagreement on three logically stated statements. So, the researchers have measured it as continuous random variable that can be measured through multiple linear regression models.

Explanatory Variables

Independency of Internal Audit (IIA): Independence of internal allows the audit activity to conduct work and be perceived to conduct work without interference by the entity under audit and independence is a key factor for the internal audit activity to add value. According to [17], a five point Likert scale was provided ranging from: a scale of 1 to 5 where 1=Strongly Disagree, 2=Partially Disagree, 3=Agree, 4=strongly agree, 5=totally Agree was used to measure independence of internal audit. Finally, the study finds out the positive and significant relationship between internal audit independence and performance.

Competency of Internal Audit Team (CIAS): The audit activity needs a professional staff that collectively has the necessary qualifications and competencies to conduct the full range of audits required by the mandate. Auditors must comply with minimum education requirements established by their relevant professional organizations and standards.

Internal Audit standards (IAS): Professional audit standards, such as the international professional practices framework (IPPF) promulgated by the IIA, support the implementation of the previous elements and provide a framework to promote quality audit work that is systematic, objective, and based on evidence. Audit activities 
should conduct their work in accordance with recognized standards. Conformance with the standards is seen as a key factor for the internal audit activity to add value to the governance process. The authors have measured 5point Likert scale

Management support (MS): The legitimacy of the audit activity and its mission should be understood and supported by a broad range of elected and appointed public sector officials, as well as by the media and involved citizens. This means the internal audit activity is credible

Formal Mandate of Internal Audit (FM): Internal auditing is required by law or regulation where the organization is based was responded. The external regulatory environment may impact the capability of the internal audit activity. The researchers have measured 5- point Likert scale

Table 1. Summary of variables definition and scale of measurement

\begin{tabular}{|c|c|c|c|}
\hline Variables incorporated & Symbol & Unit of measurement & Sign Expected \\
\hline \multicolumn{3}{|c|}{ Dependent variable } \\
\hline Organizational performance & OP & 5- point Likert scale & \\
\hline \multicolumn{4}{|c|}{ Explanatory variables } \\
\hline Independence of Internal Audit & IIA & 5- point Likert scale & + \\
\hline Competency Of Internal Audit Staff & CIAS & 5- point Likert scale & + \\
\hline Internal audit standards & IAS & 5- point Likert scale & + \\
\hline Formal Mandate of Internal Audit & FM & 5- point Likert scale & + \\
\hline Management Support & MS & 5- point Likert scale & + \\
\hline
\end{tabular}

Source: Researcher's own Construction development (2019)

\subsection{Assumption of Classical Linear Regression Model}

The following diagnostic tests were carried out to ensure that the suits the basic assumption of classical linear model. Among the assumption, the researcher conducted four basic diagnostic tests to check if the data meet the requirement. Normality, Multicollinearity, autocorrelation, and heteroscedasticity tests were undertaken.

Normality: to check for normality, descriptive statistics were used. Jarque-Bera test statistical probability, Kurtosis and Skewness of the distribution of the data were examined.

Multicollinearity: the existence of strong correlation between the independent variables was tested using variables correlation coefficients (CC); condition index (CI) and variance inflation factor (VIF).

Heteroscedasticity: to avoid the problem of heteroscedasticity of disturbance terms, Breusch-Pagan-Godfrey test was employed in establishing the relationship.

Autocorrelation: to check if there is a pattern in the errors, the Breusch-Godfrey Serial Correlation LM Test was conducted.

\subsection{Reliability Test}

To measure the consistency of the questionnaire particularly the 5 point Likert- scale have developed by the researchers. To carry out the reliability analysis, Cronbach's Alpha $(\alpha)$ is the most common measure of scale reliability and a value greater than 0.70 is very acceptable and the reliability value $(\alpha)$ greater than 0.60 is also acceptable [4] and [5]. Data collected from pilot test was analyzed using SPSS (Statistical Package for Social Sciences) version 21.0

\subsection{Methods of Data Analysis}

After accomplishment of data collection procedure, it was classified as per each variable; the qualitative data was coded to be measured quantitatively. In this research, data was analyzed by the help SPSS version 21.0 and Eviews version 9 in order to get the reliable finding.

\subsection{Econometrics Model Specification}

Performance of the organization is continuous random variable in nature that could be measured through multiple linear regression models. A model is said to be linear when it is linear in parameters. Linear regression model can be either simple or multiple. Simple linear regression model is used when there is only one independent variable. In this research multiple linear regression models were employed because, the study depends on more than one explanatory variable. Hence, both 9 explanatory variables such as (Independence of Internal Audit (IIA), Competence of Internal Audit Team (CIAS), Internal Audit Standard (IAS), A Formal Mandate of Internal Audit (FM), Management Support (MS), and dependent (public sector performance (PSP) has assumed to have linear relationship. The researchers developed the model as follow: In the multiple linear regression model, the regressed (dependent variable (PSP) is a linear function of IIA, CIAS, IAS, FM, and MS, (independent variables) corresponding to the explanatory variables and a random disturbance or error. The model 
also has an intercept. Designating the regressed by OP, the independent variables by IIA, CIAS, IAS, FM, URA, MS, CL, and OIA and the random disturbance- by $\boldsymbol{u}$, the model is given by the following expression as:

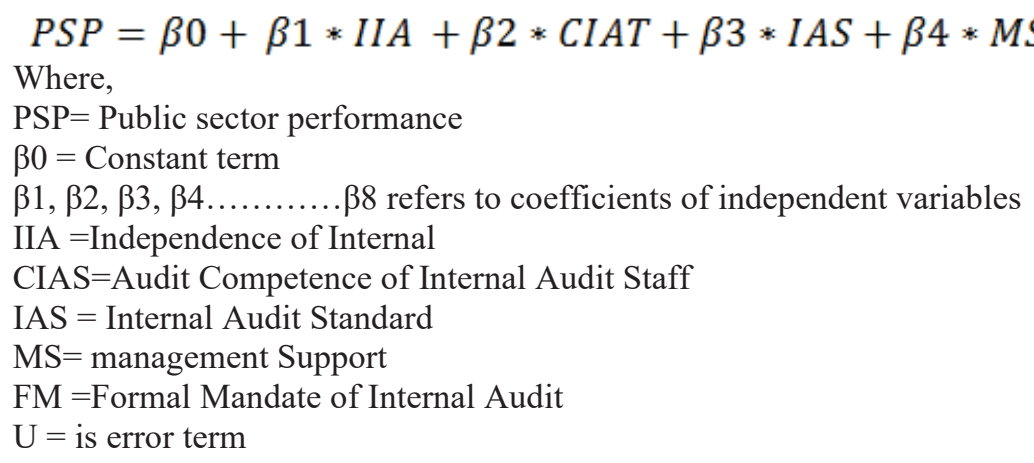

\subsection{Ethical Considerations}

The following ethical considerations have been given attention by the researchers and enumerators while conducting the research that includes voluntary participation, no harm will to participants, anonymity and confidentiality, not deceiving the subjects and privacy of participants. Conserving the voluntary participation of respondents, no participants were forced to take part in the research and participants will free to withdraw from the research at any moment. With regarding to harm to participants, the researcher ensured that there is no any physical or psychological harm done to the participants as a result of the study. When it comes to Anonymity and confidentiality, all information gathered during the study will be handled confidentially and permission from the participants was obtained for all information to be shared publicly. Not deceiving the subjects since participants will be informed clearly about the aim, purpose and procedures of the study and will not deceived in any way. Finally Privacy of participants the privacy of the participants will be respected.

\section{Results}

This section of paper is deals about analysis, interpretation and discussion of data that collected from one hundred 100 respondents out of the 101 total internal auditors. This implies that the response rate of $(9.10 \%$ which indicates almost all of respondents were participated in the process of data collection. Then, the analysis of both descriptive and inferential has been done by using the statistical package for social science version 21.0 on 90 questionnaire properly filled and collected by researcher.

\subsection{Summary of Descriptive Statistics}

Table 2. Summary of Descriptive Statistics for all Variables incorporated in the model

\begin{tabular}{|c|c|c|c|c|c|}
\hline & $\mathrm{N}$ & Minimum & Maximum & Mean & Std. Deviation \\
\hline OP & 90 & 1.00 & 5.00 & 3.0246 & .73139 \\
\hline IIA & 90 & 1.00 & 5.00 & 2.6513 & 1.12443 \\
\hline CIAS & 90 & 1.00 & 5.00 & 2.9310 & 1.22301 \\
\hline IAS & 90 & 1.00 & 5.00 & 3.0056 & 1.43304 \\
\hline MS & 90 & 1.00 & 5.00 & 3.2396 & .85857 \\
\hline FM & 90 & 1.00 & 5.00 & 2.9406 & .96214 \\
\hline
\end{tabular}

Sources: Questionnaire (2019)

Organizational performance (OP) was the dependent variable of this study. As indicated in the above table 2, the organizational performance of Bureaus (OP) shows that Bureaus achieved on average a positive organizational performance. For the total sample, the overall mean of OP was 30.246 percent with a maximum of 5 and a minimum of 1 Likert scale values. Regarding the standard deviation, it is mean to both sides by 73.139 percent, which indicate there was high variation from the mean. This implies that bureaus need to optimize the use of their assets with the help of internal audit staffs to increase the organizational performance of the bureaus.

With regard to the independency of internal audit staff (IIA), the overall mean was 26.513 percent. This implies that on average, most bureaus' independency of internal audit staff was contributing about organizational performance of the bureaus in SNNPRS. The minimum and maximum values of the under writing are one and five respectively. The mean value of underwriting risk overall deviates from its mean to both sides by 1.12443 percent.

The mean of the internal audit standards (Competency of Internal Audit Staff (CIAS) was 2.9310 percent. 
CIAS was slowly dispersed from its mean value with the standard deviation of 1.22301 percent. The maximum and minimum values of the size of the company were five and one respectively.

The mean of the internal audit standards (IAS) was 3.0056 percent. This implies that IAS averagely contributes to OP at about 3.0056. IAS was slowly dispersed from its mean value with the standard deviation of 1.43304 percent. The maximum and minimum values of the size of the company were five and one respectively.

The average value of the management support to internal audit work (MS) was 3.2396 percent. This implies that on average, the management support to internal auditors increased by .85857 percent. While the maximum $\&$ minimum values of premium growth were $5 \& 1$ percent respectively.

Regarding Formal mandate of internal audit (FM), the mean was 2.9406 indicating that competent leadership of the public organizations selected as the sample on average increased by $2.9406 \%$. The standard deviation is .96214 percent, and maximum of 5 and the minimum of 1 percent respectively.

\subsection{Reliability Analysis}

To measure the consistency of the questionnaire particularly the Likert-type scale the reliability analysis is essential in reflecting the overall reliability of constructs that it is measuring. To carry out the reliability analysis, Cronbach's Alpha $(\alpha)$ is the most common measure of scale reliability and a value greater than 0.700 is very acceptable and according to Cronbach's, a reliability value $(\alpha)$ greater than 0.600 is also acceptable.

Table 3. Table Reliability Statistics

\begin{tabular}{|c|c|c|}
\hline Cronbach's Alpha & $\begin{array}{c}\text { Cronbach's Alpha Based on } \\
\text { Standardized Items }\end{array}$ & N of Items \\
\hline 0.782 & 0.786 & 5 \\
\hline
\end{tabular}

Sources: Questionnaire (2019)

From table 3 above, the value for Cronbach's Alpha $(\alpha)$ was 0.782 is more than 0.70 for all variables which is acceptable. When these calculated reliability values for Cronbach's Alpha Based on Standardized Items is $0.786^{\approx 0.80}$, and compared with the minimum value of alpha 0.60 advocated by then the responses generated for all of the variables 'used in this research were reliable enough for data analysis [4]. This implies that the data incorporated in SPSS is reliable.

\subsection{Tests of Classical Linear Assumptions}

\subsubsection{Normality Test}

The Classical Linear Regression Model assumes that the error term is normally distributed with the mean of error being zero as positive error will offset the negative error. According to [12] testing single or joint hypothesis tests about the model parameter, the normality assumption (ut $\sim \mathrm{N}(0, \sigma 2)$ (i.e. the errors are normally distributed) must be fulfilled. In this study, the normality of the data was checked with the popular Jarque-Bera test statistic. If the residuals are normally distributed, the Jarque-Bera statistic would not be significant at 5 percent significant level meaning disturbance to be normally distributed around the mean. This means that the $\mathrm{p}-$ value given at the bottom of the normality test screens should be bigger than 0.05 . Jarque-Bera also formalized this by testing the residuals for normality and testing whether the coefficient of skeweness and kurtosis are close to zero and three respectively.

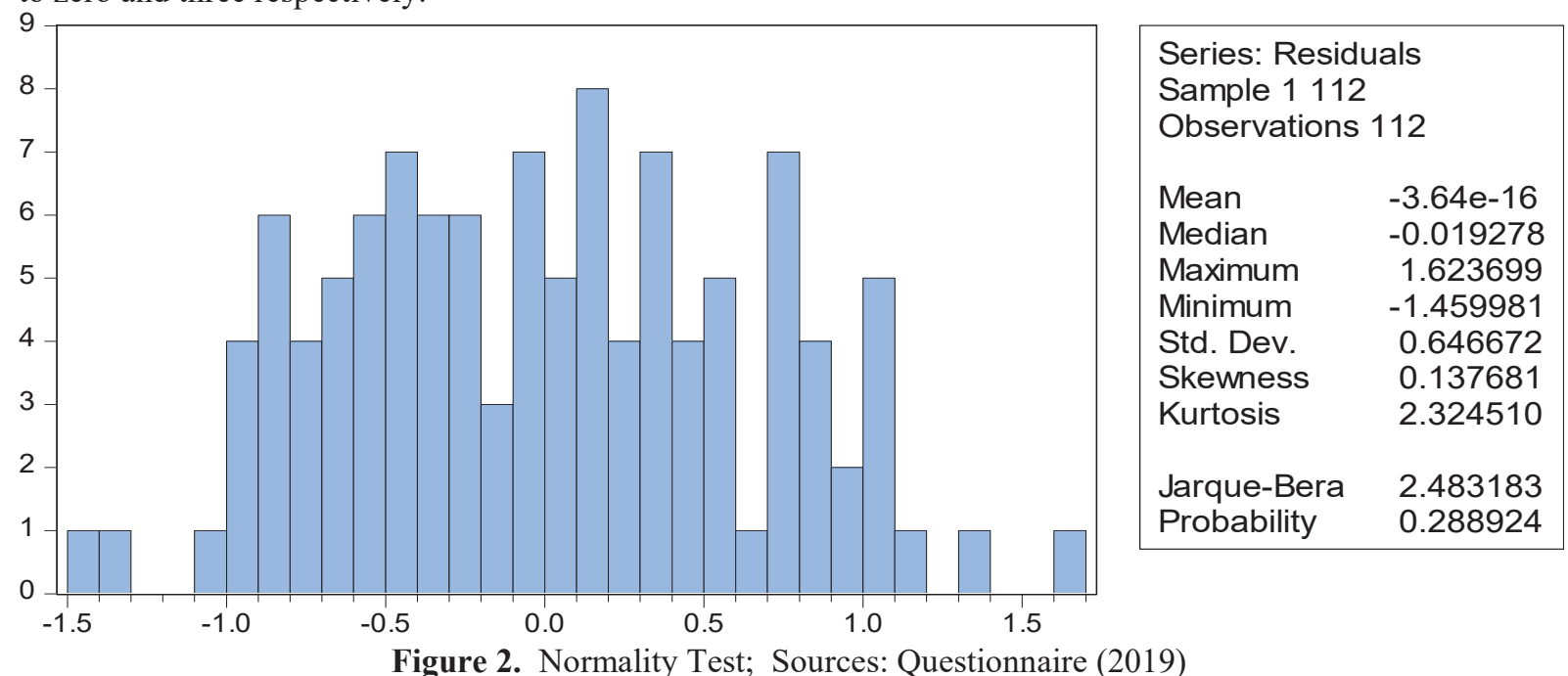

The normality test result of OP model in figure 2 above shows that, the histogram was bell-shaped and the Jarque -Bera statistic has a P-value of (0.288924) implies that the p-value for the Jarque-Bera test for this models 
is more than 0.05 and the coefficient of skeweness and kurtosis are close to zero (0.137681) and three (2.324510) respectively. So that, the result indicates that the errors were not normally distributed and there was no problem of normality on the OP model. Based on the results shown above, the p-values is insignificant for the model, bell shaped histograms from software applications and the researcher concluded that there is no normality problem on the data used for this study

3.3.2. Test of Heteroscedasticity: $\operatorname{var}(u t)=\sigma 2<\infty$

Among the OLS assumptions one of the diagnostic tests conducted in this study is heteroscedasticity test. This theoretically expressed as by Brooks $(2008$, p.133) 'var $(u t)=\sigma 2$ '; it has been assumed that the variance of the errors is constant, $\sigma 2$. In the classical linear regression model, one of the basic assumptions is Homoscedasticity assumption that states as the probability distribution of the disturbance term remains same for all observations. That is the variance of each of disturbance term is the same for all values of the explanatory variable. However, if the disturbance terms do not have the same variance, this condition of non-constant variance or nonhomogeneity of variance is known as heteroscedasticity. Accordingly, in order to detect the heteroscedasticity problems, Breusch-Pagan test was utilized in this study. This test states that if the p-value is significant at 99 confidence interval, the data has Heteroscedasticity problem, whereas if the value is insignificant (greater than $0.01)$, the data has no Heteroscedasticity problem.

Table 4. Heteroskedasticity test for OP Model

\begin{tabular}{|c|c|c|c|}
\hline \multicolumn{4}{|c|}{ Heteroskedasticity Test: Breusch-Pagan-Godfrey } \\
\hline F-statistic & 1.220658 & Prob. F $(8,103)$ & 0.2944 \\
\hline Obs*R-squared & 9.698997 & Prob. Chi-Square(8) & 0.2868 \\
\hline Scaled explained SS & 5.432385 & Prob. Chi-Square(8) & 0.7105 \\
\hline
\end{tabular}

Sources: Questionnaire (2019)

Accordingly, table 4 above shows that, all three cases the F-statistic, Obs*R-squared, and Scaled explained $\mathrm{SS}$ tests give the same conclusion that there was no significant evidence for the presence of Heteroscedasticity in Op model. Since the p-values in all of the cases were above 0.01 .

3.3.3. Test of Multicollinearity

An implicit assumption that is made when using the panel least square estimation method is that the independent variables are not correlated with one another. If there is no relationship between the explanatory variables, they would be said to be orthogonal to one another. If the explanatory variables were orthogonal to one another, adding or removing a variable from a regression equation would not cause the values of the coefficients on the other variables to change. If an independent variable is an exact linear combination of the other independent variables, then we say the model suffers from perfect colinearity, and it cannot be estimated by OLS. As shown in the Collinearity table 5 the tolerance levels for all variables are greater than 0.10 and the VIF value are less than 10 (see table 5 below). This indicates that there were no Multicollinearity problems that alter the analysis of the findings; rather it leads to the acceptance of R-value, tolerance and VIF values.

Table 5. Collinearity Statistics

\begin{tabular}{|c|c|c|}
\hline \multirow{2}{*}{ Variables } & \multicolumn{2}{|c|}{ Collinearity statistics } \\
\cline { 2 - 3 } & Tolerance & VIF \\
\hline IIA & .784 & 1.275 \\
\hline CIAS & .856 & 1.168 \\
\hline IAS & .661 & 1.512 \\
\hline MS & .821 & 1.219 \\
\hline FM & .832 & 1.202 \\
\hline
\end{tabular}

Sources: Questionnaire (2019)

\subsection{Test of Autocorrelation}

Data were assessed to ensure that the autocorrelation is not a threat for the use of OLS for analysis. This assumption can be tested with the Durbin-Watson test which test for serial correlation between errors and the value closer to 2 are acceptable the Durbin-Watson statistics value are close to 2 suggests that there is no autocorrelation among error terms.

Table 6. Breusch-Godfrey Serial Correlation LM Test

\begin{tabular}{|c|c|c|c|}
\hline \multicolumn{3}{|c|}{ Breusch-Godfrey Serial Correlation LM Test: } & \\
\hline F-statistic & 0.153794 & Prob. F(2,101) & 0.2987 \\
\hline Obs*R-squared & 0.340052 & Prob. Chi-Square(2) & 0.2661 \\
\hline
\end{tabular}

Sources: Questionnaire (2019) 
As it can be seen from the above tables Breusch-Godfrey Serial Correlation LM Test of Serial correlation that computed from E-views 9 results the P-value of both F-statistic and Chi-Square for OP model were (0.2987) and (0.2661) respectively, which were greater than the significance level of 5 percent. As described on appendix2 and table 7 below, in other way the Durbin-Watson statistics value are 2.060 is more than 2 suggests that there is no autocorrelation among error terms. Therefore, it can be concluded that, the covariance between residuals is zero and absence of serial correlation problem was found conclusively from the LM tests.

\subsection{The Regression Results (Inferential Statistics) and Hypothesis Testing}

Table 7. Regression Results

\begin{tabular}{|c|c|c|c|c|c|c|c|c|}
\hline \multicolumn{9}{|c|}{$\mathrm{R}=0.467^{\mathrm{a}}, \mathrm{R}^{2}=0.281$, Adj. $\mathrm{R}^{2}=0.158$} \\
\hline & \multirow[t]{2}{*}{ Model } & \multicolumn{2}{|c|}{$\begin{array}{l}\text { Unstandardized } \\
\text { Coefficients }\end{array}$} & \multirow{2}{*}{$\begin{array}{c}\begin{array}{c}\text { Standardized } \\
\text { Coefficients }\end{array} \\
\text { Beta } \\
\end{array}$} & \multirow{2}{*}{$\mathrm{t}$-Value } & \multirow{2}{*}{ Sig. } & \multicolumn{2}{|c|}{$\begin{array}{l}\text { Collinearity } \\
\text { Statistics }\end{array}$} \\
\hline & & $\mathrm{B}$ & Std. Er & & & & Tolerance & VIF \\
\hline \multirow{6}{*}{1} & Constant & 1.383 & .543 & & 2.548 & .012 & & \\
\hline & IIA & .144 & .064 & .222 & 2.255 & $.026^{*}$ & .784 & 1.275 \\
\hline & CIAS & .118 & .056 & .197 & 2.095 & $.039 *$ & .856 & 1.168 \\
\hline & IAS & -.027 & .055 & -.052 & -.487 & .627 & .661 & 1.512 \\
\hline & MS & .247 & .082 & .290 & 3.020 & $.003 * *$ & .821 & 1.219 \\
\hline & FM & .160 & .073 & .210 & 2.200 & $.030 *$ & .832 & 1.202 \\
\hline
\end{tabular}

$* *$ P- value $<0.01, *$ p-value $<0.05$ level of Confidence, $\mathrm{N}=112$

Sources: Questionnaire (2019)

\section{Fitted model}

$\mathrm{PSP}=1.383+0.144 * \mathrm{IIA}+0.118 *$ CIAS $-0.027 * \mathrm{IAS}+0.247 * \mathrm{MS}+0.160 * \mathrm{FM}+\mathrm{Err}$

The OLS result of was presented in table 7 above R-squared was measured the goodness off it of the explanatory variables in explaining the variations in organizational performance of bureaus in SNNPRS. As shown in the table above, R-squared and the Adjusted-R- squared statistics of the model were 28.1 percent and 15.8 percent respectively. The result indicates that 15.8 percent variation in the dependent variable was explained by the explanatory variables in the model. That means the explanatory variables (such as Independence of Internal Audit (IIA), Competence of Internal Audit Team (CIAT), Internal Audit Standard (IAS), A Formal Mandate of Internal Audit (FM), Management Support (MS)) are jointly explain about 15.8 percent of the variation in the organizational performance of the bureaus. The remaining 84.20 percent of the variation in the organizational performance of the bureaus (as measured by Likert scale) explained by other variables which are not included in the model. According to [21] a high R-square or adjusted R- Square of above $60 \%(0.60)$ is required for studies in the 'pure science' field because the behavior of molecules and/or particles can be reasonably predicted to some degree of accuracy in science research; while an R-square or adjusted RSquare as low as $10 \%$ is generally accepted for studies in the field of arts, humanities and social sciences because human behavior cannot be accurately predicted, therefore, a low R-square is often not a problem in studies in the arts, humanities and social science field. Besides, the, F- statistics (3.594) in model summary and ANOVA with (p-value of 0.001) which is used to test the overall significance of the model was presented and indicates the reliability and validity of the model at 1 percent level of significance. This tells us that the model as a whole is statistically significant. The coefficients of Independence of Internal Audit (IIA) 0.144, competence of Internal Audit staff (CIAS) 0.118, management support (MS) 0.247, and a formal Mandate of Internal Audit (FM) 0.160 leads to $0.144,0.118,0.247$ and 0.160 percent increase in public sector performance respectively. Whereas, the coefficient of negative internal audit standards - 0.027 shows that one unit changes in internal audit standard (IAS) lead to a negative direction changes on dependent variable (PSP) of the selected bureaus.

Let us discus each variables incorporated in the model one by one as by testing hypothesis:

The result of this study shows that independence of internal audit with standardized coefficient of regression $[\beta=0.144]$ has positive and statistically significant since ( $p$-value of $0.026>0.05$ ) Hence, hypothesis H1 stated as "Independence of the internal auditor has positive and significant impact on organizational performance "is accepted. This finding is consistent the finding of other studies results [17] and [23]who found out the positive and significant relationship between internal audit independence and performance in their study areas. The regression result of the model regarding independence of internal audit was also clearly evidenced that there is statistically significant and positive relationship between independency of internal audit and organizational performance in public sector as far as the sign is positive. This implies that more independency the auditor contributes to the effectiveness of an organization.

Regarding to the competency of internal audit staff with coefficient of regression of competency of internal audit staff, $[\beta=0.118]$ is positive and statistically significant with $p$-value $(0.0386>1 \%, 5 \%)$ level of significance. Therefore, hypothesis $\mathrm{H} 2$ stated as "competency of internal audit staff has positive and significant impact on 
organizational performance" is accepted. This finding is consistent with that of [18] , [23] and [26]. It implies competency of internal audit staff has positive and significant relationship with performance. This indicates increase in competency of internal audit team in the organization has positive influence on performance of the organization since it leads to the effective resource allocation.

With regarding to internal audit standard with coefficient of regression of competency of internal audit standard, $[\beta=-0.027]$ is negative and statistically insignificant with $p$-value $(0.627>1 \%, 5 \%$ and $10 \%)$ level of significances. Therefore, hypothesis H3 stated as "internal audit standard has positive and significant impact on the public sector performance" is not accepted (rejected). This indicates that increasing internal audit standard in the organization has no influence on performance of the organization since it leads to the ineffective resource allocation.

The result of this study shows that management support with standardized coefficient of regression $[\beta=0.247]$ has positive and statistically significant since ( $\mathrm{p}$-value of $0.0032<0.01$ ) Hence, hypothesis H4 stated as "management support has positive and significant impact on organizational performance "is accepted. This finding is consistent with finding of other studies results [22], [15] and [23]. Because they found out the positive and significant relationship between management support and performance in their study areas. The regression result of the model indicates management support and organizational performance in public sector are interrelated.

Table 8. Summary of Expected and Actual Influence of Explanatory Variables on OP

\begin{tabular}{|c|c|c|c|c|}
\hline & Hypothesis & Expected & Actual result & Decision \\
\hline IIA & H1: & Positive \& significant & Positive \& significant & Accepted \\
\hline CIAS & H2: & Positive \& significant & Positive \& significant & Accepted \\
\hline IAS & H3: & Positive \& significant & negative\& insignificant & Rejected \\
\hline MS & H4: & Positive \& significant & Positive \& significant & Accepted \\
\hline FM & H5: & Positive \& significant & Positive \& significant & Accepted \\
\hline
\end{tabular}

Sources: Questionnaire (2019)

\section{Conclusions \& Recommendation \\ Conclusions}

Conclusion is the process of making generalization based on findings of sample to total population. Therefore, the findings revealed from this study were generalized to all bureaus in southern Ethiopia as follow: In this paper, the researcher explores the impact of internal audit quality on organizational performance of public sector bureaus. By keeping this objective in mind, the researcher collected the primary data through self-administrated or (structured) questionnaire. By using SPSS version 21.0, the analysis of both descriptive and inferential statistics has been done.

Based on the findings from the descriptive analysis, the researchers had concluded that bureaus were averagely generating positive organizational performance. Based on the findings from the regression analysis of the model, the researchers concluded that the organizational performance of was best explained by the explanatory variables included in the model.

The conclusion that can be drawn from the findings in the first hypothesis is that hypothesis H1 stated as "independence of the internal auditor has positive and significant effect on organizational performance "is accepted.; which means an increase on the value of independency of internal audit leads to an increase on organizational performance of bureaus in SNNPRS measured by five point Likert scale.

Based on the findings related to the second hypothesis, under the summary of the findings was, hypothesis H2 stated as "competency of internal audit staff has positive and significant effect on organizational performance" is accepted.; which shows that an increase on the value of this variable leads to increase in organizational performance public sector bureaus in southern Ethiopia.

The conclusion that can be drawn from the findings of the third hypothesis is that stated, as hypothesis H3 stated as "internal audit standard has negative and insignificant impact on organizational performance" is not accepted. This indicate increase in independence of internal audit standard in the organization has no influence on performance of the organization since it leads to the in effective resource allocation.

Additionally, the findings of the fourth hypothesis are that stated, as hypothesis H4 stated as "H4 stated as "management support has positive and significant effect on organizational performance "is accepted. The regression result of the model with regarding management support clearly evidenced that one unit increase in the variable management support causes increase in organizational performance in public sector bureaus in southern Ethiopia

Concerning the findings related to fifth hypotheses, stated as "formal mandate of internal audit has positive influence on organizational performance" is accepted because the coefficient of regression is $[\beta=0.160]$ is 
positive and significant at $1 \%, 5 \%$ and $10 \%$ level of significance because p-value of $0.030>5 \%$ level of significance. This implies that increase in one unit of the variable formal mandate of internal audit has influence on organizational performance of public sector bureaus.

\section{Recommendations}

The study has shown a clear understanding of internal audit quality and its influence on public sector performance. This encourages the efforts of internal auditor to improve their organizational performance, which can be done through effective internal audit function. Therefore, based on the major findings of the study the following recommendations are made:

The finding of this research proved that the independency of internal audit (IIA), competency of internal staff (CIAS), audit management support (MS), and formal mandate of internal audit (FM) have statistically significant influence on the organizational performance in the public sector offices in southern Ethiopia. Hence, the recommendation was forwarded to the based on statistically significant variables as follow.

Based on conclusion that can be drawn from the first hypothesis is proved that an increase on the value of independency of internal audit leads to an increase on organizational performance of bureaus in SNNPRS measured by five point Likert scale. Hence, the bureaus should work on internal audit independence (work without interference) as far as independence allows the audit activity and be perceived to conduct work without interference by the entity under audit and independence is a key factor for the internal audit activity to add value as this research identified there is positive relationship between organizational performance and the independency of internal audit. Successful implementation of internal audit tasks means that it must be independent, i.e., company management should in no way influenced by its work, information, conclusions, and evaluations.

The finding related to the second hypothesis shows that an increase in the value of this variable leads to increase in organizational performance public sector bureaus in SNNPRS. The internal auditors of the public sector bureau are recommended to maintain and improve their effective contribution for the organizational performance in their office by the competency of internal auditors because the audit activity needs a professional staff that collectively has the necessary qualifications and competencies to conduct the full range of audits required by the mandate. Auditors must comply with minimum education requirements established by their relevant professional organizations and standards. Internal audit staff professional certification(s) internal audit staff are members of the IIA internal audit staff members have at least 40 hours of formal training per year in different countries in the world as suggested by [16]. The internal auditors' technical competence has impacts on the performance of the organization and the audit staff needs to have competence in risk profiling in order to effectively run their activity by applying professional expertise that they have equipped.

Additionally, the findings of the fourth hypothesis is the regression result of the model clearly evidenced that one unit increase in the management support causes increase in public sector performance of bureaus in SNNPRS. In fact, management support is the legitimacy of the audit activity and its mission should be understood and supported by a broad range of elected and appointed public sector officials, as well as by the media and involved citizens. This means the internal audit activity is credible within the organization with management support. In the current study, it found out that management support has positive and statistically significant influence on organizational performance. This implies the, management support of internal audit department has significant impact on internal audit quality in one hand and organizational performance in other hand. Hence, the bureaus should work on management support for internal audit activity in their organizations more the current one to sustaining the support to internal audit work efficient and effective in safeguard public resources.

Finally, the study finding related to fifth hypotheses, the study evidenced that formal mandate of internal audit has positive and statistically significant influence on organizational performance" which implies that increase in one unit of the variable formal mandate of internal audit has positive influence on influence on organizational performance of public sector bureaus. The audit activity powers and duties should be established by the public sector constitution, charter, or other basic legal document. Formal mandate of the bureaus in SNNPRS would address procedures and requirements of reporting and the obligation of the audited entity to collaborate with the auditor. A global average of three quarters of the public sector respondents indicated that internal auditing was required by law or regulation where their organizations were based [16]. Internal auditing is required by law or regulation where the organization is based was responded. The bureaus should take in to account the external regulatory environment may affect the capability of the internal audit activity in the bureaus because having a legal mandate may give more legitimacy to the internal audit activity.

\section{Limitations \& Direction for the Future Research}

Any study cannot be free from limitations. Accordingly, there are some limitations in current study. Originally, it focused only on assessing the impact of internal audit quality on organizational performance of public sector 
bureaus in southern Ethiopia. The explanatory variables incorporated in the model have only explained $15.80 \%$ of the model. The remaining $84.2 \%$ of changes in the organizational performance was explained by other explanatory variables that not included in the model. The other researcher should incorporate more variables to improve adjusted $\mathrm{R}^{2}$ with the same topic at the same study area. In other way, the findings of this study may be difficult to generalize about all bureaus in all regional states and at national. Hence, this study can be improved if it will be done at other regions and national level by comparing internal audit quality on organizational performance of public sector by increasing sampling different economic sectors.

\section{Acknowledgements}

First, we would like to give unlimited thanks for almighty God for helping us in all our entire journey. Next to God, we appreciate BSTL college Hawassa, Ethiopia which is one the top private colleges in Ethiopia that striving to serve the community by providing trainings in both TVET and undergraduate programs in business, Agro processing and IT fields and supporting problem solving researches widely for supporting our research work. In addition, we would like to express our thanks to the staff members of BSTL college especially Ato Solomon Aregay (Vice dean of the college), Ato Nigatu G/ Hiwot (Department head of accounting \& Finance) and all remaining staff of BSTL College. On other hand, the authors would like to express heartfelt appreciation to the anonymous editors and reviewers in developing this article for publication.

\section{REFERENCES}

Amina Ahmed Muhammed (2016). The Role of Internal Auditors in Private and Public Organizations of Jimma Zone Selected Weredas, Ethiopia International Journal of Scientific and Research Publications, 6 (11). PP $152-168$

Amanuddin Shamsuddin (2014). Factors That Determine the Effectiveness of Internal Audit Functions In the Malaysian Public Sectors. International Journal of Business, Economics and Law, Vol. 5, Issue 1 pp 9-17

Cohen A. \& Sayag, G. (2010), "the Effectiveness of Internal Auditing: An Empirical Examination of its Determinants in Israeli Organizations": Australian Accounting Review, 20(3), 296-307.

Cronbach's, L. J. (1951), “Coefficient alpha and the internal structure of tests": Psychometric, 16, pp.297-334.

C.R. Kothari. (2004). Research Methodology. 2nd edition. Published by New Age International (P) Ltd., Publishers, India. ISBN (13): 978-81-224-2488-1

Dawuda. (2010). The Effectiveness of the Internal Audit Units in the Public Sector in Promoting Good Corporate Governance: The Case of the Metropolitan, Municipal and District Assemblies in the Northern Region of Ghana.

Enofe,Dr C. J. Mgbame, V. E. Osa-Erhabor*,A. J. Ehiorobo (2013). The Role of Internal Audit in Effective Management in Public Sector. Research Journal of Finance and Accounting www.iiste.org ISSN 2222-1697 (Paper) ISSN 2222-2847 (Online)Vol.5, No.23, 2014

Faudziah Hanim Fadzil, HasnahHaron, Muhamad Jantan, (2005),"Internal auditing practices and internal control system", Managerial Auditing Journal, Vol. 20 Iss: 8 pp. 844 - 866

Green, S. B. (1991). How many subjects does it take to do a regression analysis? Multivariate Behavioral Research, 26, 499 - 510.

Gezahegn Getahun .(2017). The impact of internal audit on public organization performance: The case of Yirgalem town: MSC thesis submitted to the department of Accounting \& finance for partial fulfillment of MSC in accounting \& finance . unpublished.

Greene, W.H., (2008). Econometric Analysis.6th edition, Prentice-hall Inc. Upper Saddle River, New Jersey.

Gujarati, D. (2009). Basic Econometric, McGraw-Hill Education Books forth Ed. Ltd. India.

Hair, J. (2006). Multivariate data analysis, 6th edn. Pearson Education, New Jersey. Hellman N.(2011), " Chief Financial Officer influence on Auditing Plan": International Journal of Auditing, 15(433),pp.247-74

Sayyar, R. Basiruddin, S. Z. Abdul Rasid, and M. A. Elhabib (2015). The Impact of Audit Quality on Firm Performance: Evidence from Malaysia. Journal of Advanced Review on Scientific Research Vol. 10, No.1. Pages 1-19

Hawa Aliyi (2016). Factors that Identify the Effectiveness of Internal Audit in Oromia Special. Zone Surrounding Finfinne Administration Finance and Economic Development Offices, Ethiopia. A Research Project paper Submitted to the Department of Accounting and Finance College of Business and Economics Presented in Partial Fulfillment of the Requirements for the Degree of Master of Science in Accounting and Auditing Addis Ababa University Ethiopia

Institute of Internal Auditors Research Foundation .(2014). The Role of Auditing in Public Sector Governance: Supplemental Guidance:, 2nd Edition Elizabeth Mac Rae, CGAP Diane van Gils, Ph D Nine Elements Required for Internal Audit Effectiveness in the Public Sector

Kirima N. (2016). Factors Affecting the Performance of the Internal Audit Function In Government Ministries in Kenya: A Research Project Submitted to the Chandaria School of Business in Partial Fulfillment of the 
Requirement for the Degree of Masters in Business Administration (MBA) United States International University - Africa

Mihiret,D.G \& Yismew,AW (2007), "Internal Audit effectiveness an Ethiopian public sector case study" : Managerial Auditing Journal,22(5),470-84

Morteza Ziaee. (2014).the effect of audit quality on the performance of listed companies Tehran Stock Exchange: International Letters of Social and Humanistic Sciences Online: 2014-02-08 ISSN: 2300-2697, Vol. 21, pp 36-43 doi:10.18052/ www.scipress.com/ ILSHS.21.36 @ 2014 SciPress Ltd., Switzerland

Okaro S. C, Okafor G. O, Egbunike F C. (2015). Audit Committee Effectiveness in Nigeria: The Perception of Professional Accountants. International Journal of Management Sciences Vol. 5, No. 2, 125-135

Peterson (2016) Answer for what should be minimum value of R-square and adjusted r-square? Available online athttps://www.researchgate.net/post/what_is_the_acceptable_r-squared_value browsed on April 18, 2019

Shewamene Hailemariam (2014) Determinants Of Internal Audit Effectiveness In The Public Sector, Case Study In Selected Ethiopian Public Sector Offices A Research Paper Submitted To The Post Graduate Office In Partial Fulfillment Of Th Requirement For The Master's Degree Of Science In Accounting And Finance (Msc.)

Tesema Geda (2018). The Role of Internal Audit Practice to Promote Good Governance inPublic Institution of Ethiopia: The Case of Jimma Zone. Global Journal ofManagement and Business Research: D Accounting and Auditing 18 (2) pp 41-55.

Taiwo Olufemi Asaolu1, Samuel Adebayo Adedokun1 and, James UnamMonday (2016). Promoting Good Governance through Internal Audit Function (IAF): The Nigerian Experience. International Business Research; 9 (5) pp. 196 up to 204. Published by Canadian Center of Science and Education

Vani (2010 Internal Audit in the Public Sector: Underdeveloped and Underused. Available onlineat.https://blogpfm.imf.org/pfmblog/2010/08/posted-by-sanjay-vani---of-107

countries-in-which-public-expenditure-and-financial-accountability-pefa-assessments-have-bee.html

Wubishet Jemaneh Deribe1 and Dereje Getachew Regasa (2018). Factors Determining Internal Audit Quality: Empirical Evidence from Ethiopian Commercial Banks. Research Journal of Finance and Accounting Vol.4, No.6 